\title{
A Mutagenic Study of $\beta$-1,4-Galactosyltransferases from Neisseria meningitidis
}

\author{
Jae Eun Park, Su-II Do", Ki-Sung Lee and Sang Soo Lee* \\ Research Center for Bio-Medicinal Resources, Pai Chai University, 439-6 Doma-dong, Seo-gu, Taejon 305-600, Korea \\ 'Department of Life science, Azou University, San 5 Wonchun-dong, Youngtong-gu, Suwon 443-749, Korea
}

Received 16 February 2004, Accepted 2 April 2004

\begin{abstract}
$\mathrm{N}$-terminal His-tagged recombinant $\boldsymbol{\beta}$-1,4-galactosyltransferase from Neisseria meningitidis was expressed and purified to homogeneity by column chromatography using Ni-NTA resin. Mutations were introduced to investigate the roles of, Ser68, His69, Glu88, Asp90, and Tyr156, which are components of a highly conserved region in recombinant $\boldsymbol{\beta}-1,4$ galactosyltransferase. Also, the functions of three other cysteine residues, Cys65, Cys139, and Cys205, were investigated using site-directed mutagenesis to determine the location of the disulfide bond and the role of the sulfhydryl groups. Purified mutant galactosyltransferases, His69Phe, Glu88GIn and Asp90Asn completely shut down wild-type galactosyltransferase activity (1-3\%). Also, Ser68Ala showed much lower activity than wild-type galactosyltransferase (19\%). However, only the substitution of Tyr156Phe resulted in a slight reduction in galactosyltransferase activity $(90 \%)$. The enzyme was found to remain active when the cysteine residues at positions 139 and 205 were replaced separately with serine. However, enzyme reactivity was found to be markedly reduced when Cys65 was replaced with serine (27\%). These results indicate that conserved amino acids such as Cys65, Ser68, His69, Glu88, and Asp90 may be involved in the binding of substrates or in the catalysis of the galactosyltransferase reaction.
\end{abstract}

Keywords: Galactosyltransferase, Mutagenesis, Neisseria meningitidis, PCR

*To whom correspondence should be addressed.

Tel: 82-42-520-5616; Fax: 82-42-520-5616

E-mail: sslee@mail.paichai.ac.kr

\section{Introduction}

$\beta$-1,4-galactosyltransferase (EC 2.4.1.22) is involved in the synthesis of many oligosaccharides of biological importance in eucaryotes ( $N$-glycan, $\mathrm{O}$-glycans, histo-blood group antigens, glycolipids, lactose, etc.), and in the synthesis of cell wall polysaccharides in prokaryotes. This enzyme catalyzes the transfer of galactose from UDP-galactose to glycoproteins or glycolipids containing $\beta$-linkage (Ram and Munjal, 1985; Paulson and Colley, 1989). cDNAs encoding galactosyltransferase genes have been isolated from human (Appert et al., 1986; Marsi et al., 1988), bovine (Narimatsu et al., 1986), and murine sources (Shaper et al., 1988). The availability of galactosyltransferase cDNA opens the way to the investigation of the structure-function relationships of galactosyltransferase by recombinant techniques. The functional domains of mammalian galactosyltransferase have been studied by various laboratories by expressing cDNA clones in both bacterial and mammalian cells (Masibay and Qasba, 1989; Aoki et al., 1990; Nakazana et al., 1993). Based on amino acid sequence similarities and conserved structural features, eucaryotic and bacterial galactosyltransferases can be classified into five families; A, B, C, D and E (Breton et al., 1998). Multi-alignment of bacterial galactosyltransferases shows three conserved regions I, II, and III, as shown in Fig. 1. Region II contains an acidic motif, EDD, surrounded by two stretches of hydrophobic residues, which exhibits hydrophobic cluster analysis (Gaboriaud et al., 1987) similarity with the DVD and DXD motifs of families A and B, respectively (Breton et al., 1998). This is located in a region of the catalytic domain that has been implicated in UDPgalactose binding by chemical (Yadav and Brew, 1990, 1991) and mutational studies (Aoki et al., 1990; Zu et al., 1995)

The structural and functional relationships of mammalian galactosyltransferase have been well studied, but bacterial galactosyltransferase is poorly understood. Recently, we cloned and expressed $\beta$-1,4-galactosyltransferase from Neisseria meningitidis and Neisseria gonorrhoeae (Park et al., 
2002). In N. meningitidis, contains a locus that consisted of three genes $(\lg t \mathrm{~A}, \lg t \mathrm{~B}$, and $\lg t \mathrm{E})$, which encode the glycosyltransferase enzymes that are required for to add of least three sugars in the lacto- $N$-neotetraose chain (Jennings et $a l ., 1995)$. Of these genes, the $\lg t \mathrm{~B}$ gene from the bacterial pathogen $N$. meningitidis is known to encode a $\beta-1,4-$ galactosyltransferase enzyme (Wakarchuk et al., 1998). The amino acid sequence of the $\beta$-1,4-galactosyltransferase of $N$. meningitidis shows homology with those of other bacterial galactosyltransferase from Haemophilus inflenza (High et al., 1993), Haemophilus ducreyi (Sun et al., 2000), Helicobacter pylori (Endo et al., 2000), Pateurella haemolytica (Potter and Lo, 1995) and Escherichia coli (Heinrichs, 1998). These bacterial galactosyltransferases are classified into family $\mathrm{C}$ (Breton $e t$ al., 1998), one of the five families of galactosyltransferases that include the $\beta$-1,3-galactosyltransferase of the rat and the $\beta$-1,4-galactosyltransferases Neisseria bacteria, which participate in the biosynthesis of the lacto-N-neotetraose terminal lipopolysaccharide structure (Gotschlich, 1994; Jennings et al., 1995). In this report, we performed mutational studies upon several conserved amino acids, and we found that the conserved acidic cluster (EDD in Region II of Fig. 1) and amino acids (Fig. 1) are important for catalysis.

\section{Materials and Methods}

Construction and cloning of the site-directed galactosyltransferase genes Eight oligonucleotides were designed to construct sitedirected mutated galactosyltransferases (Table 1). These were chosen by examining the conserved sequences of other bacterial galactosyltransferases. Mutagenesis was performed by sequential PCR (Higuchi et al., 1988). In first round PCR, the terminal sense sequence 5' CGGGATCCATGCAAAACCACGTTATCAGC 3' and internal antisense primers (Table 1) were used as a primer set. And for $2^{\text {nd }}$ round PCR, the terminal antisense sequence $5^{\prime}$ GCGGTACC GCAAATACGATGTCCATCT 3' and internal sense primers (Table 1) were used as a primer set. The pETgal4M vector containing the galactosyltrasferase gene $(\lg t \mathrm{~B})$ of $N$. meningitidis was obtained during a previous study (Park et al., 2002) and used as a template. In $1^{\text {st }}$ round PCR was performed over 30 cycles with an initial denaturation of $10 \mathrm{~min}$ at $95^{\circ} \mathrm{C}$, and cycles of $60 \mathrm{~s}$ at $95^{\circ} \mathrm{C}, 60 \mathrm{~s}$ at $55^{\circ} \mathrm{C}$ and $2 \mathrm{~min}$ at $72^{\circ} \mathrm{C}$. In the $2^{\text {nd }}$ round, terminal sense and anti-sense primers were used as a primer set to anneal the upstream and downstream flanking sequences just beyond the $\lg t \mathrm{~B}$ gene, and which contained the Bam $\mathrm{HI}$ and Kpn I recognition sequences (underlined in the terminal sense and antisense sequences). Two PCR products from the first round reactions were used as templates to produce a single annealed PCR product. The PCR conditions used were as follows: initial denaturation for $2 \mathrm{~min}$ at $95^{\circ} \mathrm{C}$ and then thirty cycles of denaturation for $1 \mathrm{~min}$ at $95^{\circ} \mathrm{C}$, annealing for $60 \mathrm{~s}$ at $55^{\circ} \mathrm{C}$, and extention for $2 \mathrm{~min}$ at $72^{\circ} \mathrm{C}$. The final PCR products were digested with Bam $\mathrm{HI}$ and Kpn I, and ligated to pET28a purchased from Novagen (Darmstadt, Germany). This ligation mixture was used to transform E. coli XL1 blue. All mutants were analyzed by DNA sequencing of the plasmid inserts by the
Table 1. Primers used in site-directed mutagenesis

\begin{tabular}{|c|c|}
\hline Primer & Sequence \\
\hline Cys65Ser & 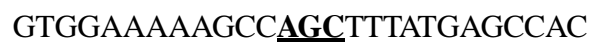 \\
\hline Ser68Ala & GCCTGCTTTATG $\underline{\text { GCCACGCCGTATTG }}$ \\
\hline His69Phe & TGCTTTATGAGC \\
\hline Glu88Gln & ATCGCCGTATTTEAGGACGACGTTTTA \\
\hline Asp90Asn & 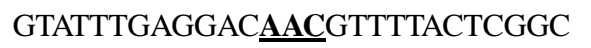 \\
\hline Cys139Ser & GTGGCGGACTACAGCGGGCGTGCCTTT \\
\hline Tyr156Phe & GGGACGGCGGGCTTTATCATTTCCAAA \\
\hline Cys198Ser & GGAATGCCGGTTAGCCAGCTCAATCCC \\
\hline Cys205Ser & AATCCCGCCTTA프CGCCCAAGAGCTG \\
\hline
\end{tabular}

dideoxy termination method. The resulting recombinants are referred to as the pETgal4 series.

Expression and purification of the recombinant enzyme After inductions $\left(4 \mathrm{~h}\right.$ at $37^{\circ} \mathrm{C}$ and $8 \mathrm{~h}$ at $25^{\circ} \mathrm{C}$ ) for several hours with isopropyl-D-thiogalactopyranoside (IPTG), E. coli BL21 (DE3) cells harboring pETgal4 series were harvested by centrifugation and resuspended in lysis buffer $(50 \mathrm{mM}$ Tris $\mathrm{pH} 8.0,300 \mathrm{mM} \mathrm{NaCl}, 20$ $\mathrm{mM}$ imidazole, $1 \mathrm{mM}$ PMSF). Cells were then sonicated using a microtip at $50 \%$ power for five 20 -s intervals on ice, and soluble and insoluble fractions were separated by centrifugation, when needed. Whole cell lysates and soluble and insoluble fractions from $0.1 \mathrm{ml}$ cultures were analyzed by $12 \%$ sodium dodecyl sulfatepolyacrylamide gel electrophoresis (SDS-PAGE), and bands were visualized by Coomassie blue staining using previously described standard procedures (Maniatis et al., 1982).

The recombinant proteins were purified by column chromatography using Ni-NTA resin (Koh et al., 2001). BL21 (DE3)/pET-gal4 series were grown in $100 \mathrm{ml}$ of LB medium containing $50 \mu \mathrm{g} / \mathrm{ml}$ kanamysin at $25^{\circ} \mathrm{C}$ in a shaking flask. When the culture reached $\mathrm{A}_{600}=0.5$, the T7 promoter was induced with $0.5 \mathrm{mM}$ IPTG for $8 \mathrm{~h}$. Cells were then harvested by centrifugation, resuspended in $30 \mathrm{ml}$ of lysis buffer, and sonicated using a multitip at $50 \%$ power for ten 1-min intervals on ice. The lysates were then centrifuged at $75,000 \mathrm{~g}$ for $90 \mathrm{~min}$, and pellets were extracted with $10 \mathrm{ml}$ of the same buffer. The combined supernatants were then loaded on a 5ml Ni-NTA column pre-washed with lysis buffer, proteins were eluted with elution buffer (50 mM Tris $\mathrm{pH} 8.0,300 \mathrm{mM} \mathrm{NaCl}, 250$ $\mathrm{mM}$ imdazole, $1 \mathrm{mM}$ PMSF), and eluted fractions were dialyzed against a storage buffer (50 mM Tris pH 8.0, $20 \mathrm{mM} \mathrm{NaCl}, 20 \%$ glycerol). The column fractions were identified at each purification step by $12 \%$ SDS-PAGE.

Galactosyltransferase assay with purified $\beta$-1,4-galactosyltransferase The galactosyltransferase assay used was a modification of a previously described method (Kim et al., 1997; Park et al., 2002). The enzyme activities of the purified proteins were measured in vitro in 30-ml reaction mixes containing $20 \mathrm{mM}$ MOPS ( $\mathrm{pH} 7.85$ ), $10 \mathrm{mM} \quad \mathrm{MnCl}_{2}, 10 \mathrm{mM} \quad \mathrm{ATP}, 20 \mathrm{mM} \quad \mathrm{N}$-acetylglucosamine (GlcNAc), and $0.8 \mathrm{pmol}\left(5 \times 10^{4} \mathrm{cpm}\right)$ of dried [ $\left.{ }^{3} \mathrm{H}\right]$ UDP- $\alpha-D-$ galactose $(60 \mathrm{Ci} / \mathrm{mmol})$ in an Eppendorf tube. After incubation at $37^{\circ} \mathrm{C}$ for $1 \mathrm{~h}$, the reaction was terminated by adding $1 \mathrm{ml}$ of distilled water. Reaction mixtures were loaded onto a 1-ml Dowex (AG1$\mathrm{X} 8$ ) pipette column pre-equilibriated with $5 \%$ sodium borate. After 
the column had been washed with $1 \mathrm{ml}$ of $5 \%$ borate solution 5 times, the amount of tritium labeled galactose $\beta 1-4 \mathrm{~N}$ actylglucosamine (Gal $\beta 1-4 \mathrm{GlcNAc})$ in each fraction was quantified using a liquid scintillation counter. In order to identify the disaccharide (Gal $\beta 1-4 \mathrm{GlcNAc})$ reaction product, the reaction mixture was loaded on a Bio-Gel P-4 column $(1.5 \times 100 \mathrm{~cm})$ preequilibriated with $5 \%$ sodium borate solution. The tritium labeled galactose incorporated in disaccharide was counted using a liquid scintillation counter.

\section{Results and Discussion}

The galactosyltransferases constitute a large and heterogeneous class of enzymes, and the amino acid sequences of galactosyltransferases from different sources show a high degree of conservation. On the basis of the type of reaction catalyzed and protein sequences, these enzymes can be classified into seven $\alpha$-galactosyltransferase and five $\beta$ galactosyltransferase groups, respectively (Breton et al. 1998). This classification also reflects the natures of the glycosidic linkages formed.

Within individual groups, proteins are expected to be evolutionally related and to have similar overall 3D structures. By combined hydrophobic cluster analysis (Gaboriaud et al., 1987) and BLAST analysis, Breton et al. (1998) searched for local homologies in the different groups of galactosyltransferases and in other glycosyltransferases. This study resulted in the definition of five families (A, B, C, D, and E) which included protein sequences of glycosyltransferases from various sources and classes. The lengths and locations of the conserved regions in galactosyltransferase vary from one family to another (Breton et al., 1998). The present study identified conserved amino acids in family $\mathrm{C}$ in galactosyltransfrase of bacterial species that infect mammals (Fig. 1). These galactosyltransferases exhibit partial homology with other protein sequences of $\beta$-1,3-galactosyltransferase from mammals (Breton et al., 1998). Yuan et al. (1997) reported that a class of signaling molecules involved in developmental processes, such as Fringe and Brainiac, may be glycosyltransferases, and found that they show local homology with bacterial galactosyltransferases. A multialignment of the three most conserved regions found in proteins of family $\mathrm{C}$ is shown in Fig. 1. Region II, which contains an acidic motif (EDD) present immediately after a vertical hydrophobic cluster, indicative of a $\beta$-strand, was found in almost all families, except family $\mathrm{D}$, which contained a consensus sequence instead, i.e., ExxxxxxxE. As this motif is widespread in different classes of glycosyltransferases, it is likely to be involved in enzyme function. The use of a UDP-sugar was found to be a common feature of enzymes belonging to families A, B, C, and E. Therefore, the acidic motif could be involved in either UDP binding and/or the catalytic process.

In this study the use of PCR to introduce mutations into the DNA sequence required either two or three steps. PCR was performed using mismatched primers as shown in Table 1 to introduce mutations into the galactosyltransferase DNA sequence. Two primary PCR reactions produced two overlapping DNA fragments, both bearing the same mutations, which were introduced into the region of overlap via primer mismatch.

As discussed previously, mutations were introduced into recombinant $\beta$-1,4-galactosyltransferases to investigate the possible roles of a conserved sequence region, which is a plausible location for a binding site for the catalytically essential cation. The entire sequences of mutants were checked by DNA sequencing to confirm the presence of the desired mutation in each case, and to ensure that no unwanted mutations were introduced by the PCR mutagenesis procedure.

E. coli BL21 (DE3) cells harboring pET-gal4 series containing the mutant galactosyl transferase gene were induced by IPTG at $25^{\circ} \mathrm{C}$ and $37^{\circ} \mathrm{C}$. Whole cell lysates were then analyzed by $12 \%$ SDS-PAGE. One major band appeared approximately at the $33-\mathrm{kDa}$ position in the case of IPTG induction (data not shown), as was previously reported by Park et al. (2002). The mutant recombinant galactosyltransferases were purified to homogeneity by Ni-NTA affinity chromatography from overexpressed cells that were grown at $25^{\circ} \mathrm{C}$ (data not shown).

In order to further investigate, the structurally related functions of galactosyl transferase, highly conserved amino acids, such as Ser68, His69, Glu88, Asp90, and Tyr156 were substituted with structurally analogous amino acids. The enzyme activities of wild type and mutant galactosyltransferases were then measured. The mutants His69Ala, Glu88Gln, and Asp90Asn showed dramatic reductions in enzyme activities as shown in Fig. 2. Substitutions of Asp90 and Glu88 into Asn90 and Gln88 severely shut down galactosyltransferase activity (1\% and $2.4 \%$ ), indicating that the acidic group formed by these amino acids may have an essential role in enzymatic activity. A recent study showed that the acidic motif (DVD) of bovine $\beta-1,4-$ galactosyltransferase is involved in metal coordination (Boeggeman and Qusba, 2002). Thus it seems that the substitutions of Glu88 and Asp90 into Gln88 and Asn90 might interrupt the coordination of $\mathrm{Mn}^{+2}$ to galactosyltransferase; moreover, the substitution of His69 into Ala69 almost abolished the emzyme activity (3.0\%), and replacing Ser68 with Ala68 reduced the activity (by 19\%). These results indicate that His69 and Ser68 in galactosyltransferase are probably involved in galactosyltransferase catalysis or are closely located to the binding sites of UDP galactose or other substrates. On the other hand, the substitution of Tyr156 with Phe156 had little affect on enzyme activity $(90 \%)$ indicating that the hydrophobic properties of tyrosine and phenylalanine may be important for the catalytic reaction. These results suggest that the hydrophobic group of tyrosine is important for the catalytic activity of galactosyltransferase.

It is well known that the internal disulfide bond of human 
Region I

\begin{tabular}{|c|c|c|c|c|c|c|}
\hline N.meningitidis & (2) & NHVISLASAA & ERRAHIADTF & GRHGIPFQFF & DALMPSERLE & QAMAELVPGL \\
\hline N.gonorrhoeae & (2) & NHVISLASAA & ERRAHIAATF & GSRGIPFQFF & DALMPSERLE & RAMAELVPGL \\
\hline H.ducreyi & (7) & NYVISLKTAD & ARRQHI IQEF & AKHNIPFQFF & DACSIENNLY & MDIEKHLPML \\
\hline P.hemolytica & (2) & NYVISLTSAQ & ERRKHIEAEF & GKQNIPFQFF & DAITPD. .LI & KEKAKAFNID \\
\hline E.coli & $(4)$ & IYIVSLKRDI & ERRNKINDVF & HRLNINFDFF & DAIDAKDPQN & KEIIDKMRLS \\
\hline H.pylori & $(40)$ & DAIYSKTFEG & GLHPLVKKHL & HPYFITQNIK & DMGITTNLIS & EVSKFYYALK \\
\hline H.influenzae & (22) & QAQFELLFSN & NLIQEIHFFD & AIYGKSNPNH & PLFQRYNENK & RLNAKGYPL. \\
\hline Consensus & & &.$r r \ldots i \ldots f$ & …i.f.ff & da....n... & $\ldots \ldots \ldots 1$ \\
\hline & & & Region II & & & \\
\hline N.meningitidis & (10) & KACFMSHAVL & WKQALDEGLP & YITVFEDDVL & LGEGEEKFLA & EDAWLQERFD \\
\hline N.gonorrhoeae & (10) & KACFMSHAVL & WEQALDEGVP & YIAVFEDDVL & LGEGAEQFLA & EDTWLQERFD \\
\hline H.ducreyi & (9) & KGCLMSHFLL & WKKCVLDDIP & YMTIFEDDII & LSDESNEFIS & DYSWVNNRFY \\
\hline P.hemolytica & (10) & IACALSHIAL & WHLAKQQNLD & YICIFEDDIY & LGNNAFELL. & ..... KTNYI \\
\hline E.coli & (10) & IACTLSHQLI & YKDMIDKNIE & WAVILEDDVI & VNEKFKKFLQ & YFNLPEKDKL \\
\hline H.pylori & (10) & LGCYASHYSL & WEKCIELNEA & . ICILEDDIT & LKEDFKEGL. & . DFLEKHIQ \\
\hline H.influenzae & $(4)$ & LGCYASHYSM & WEKCVELDYP & . I IVLEDDAK & FKNNFLEVL. & .. DFINSDKN \\
\hline onsensus & & & $n$. & . & n.f.e.l. & \\
\hline
\end{tabular}

Region III

\begin{tabular}{|c|c|c|c|c|}
\hline .menin & (33) & LESEHWGTAG YIISRKAMRF & FLDRFAALPP & EGLHPV \\
\hline N.gonorrhoeae & (33) & LESEHCGTAG YIISRKAMRF & FLDRFAVLPP & ERLHPVDLMM (97) \\
\hline H.ducreyi & (33) & LISRHFGTAS YLISKEAAKY & LILLYEKLPA & DELIAVDESI ( 94 \\
\hline P.hemolytica & (34) & LNSRHVGTAG YILTNKGAEF & LINILKTLN. & ...IPIDDLI (92) \\
\hline E.coli & $(40)$ & NKNKIRRTCS YLMNKDMAQK & LLKLTKDYGT & YRADSWKLMH (44) \\
\hline H.pylori & (36) & AYSHGVGTQG YVITPKIAKV & FKKHSRKW. & . .VVPVDTIM (38) \\
\hline H.influenzae & (32) & GFA...GATG YYLTPQAARK & FLTQSKEW. . & . .YLTVDVTM $(4$ \\
\hline onsensus & & $\underline{y} . . t \ldots a$. & fl...k... & $\ldots$...vd..m \\
\hline
\end{tabular}

Fig. 1. Multiple sequence alignment of bacterial galactosyltransferase protein sequences. The aligned protein sequences and their GenBank accession numbers are: Neisseria meningitidis $\beta$-1,4-galactosyltransferase (U25839), Neisseria gonorrhoeae $\beta$-1,4- galactosyltransferase (U14544), Haemophilus ducreyi galactosyltransferase II (AAF32397), Pasteurella hemolytica LpsA gene (U15958), Escherichia coli putative $\beta$-1,4-galactosyltransferase (AAC69683), Helicobacter pylori $\beta-1,4-$ galactosyltransferase (BAA88524) and Haemohpilus influenzae Lex1 gene (Q03974). The invariant residues in consensus are given in bold type and underlined. Dots indicate gaps. Numbers in brackets indicate the numbers of amino acids between two conserved regions. Numbers indicate amino acid residues.

galactosyltransferase has an important function in terms of its secondary structure (Wang et al., 1994). The substitution of cysteine residues with another amino acid like serine, would be expected to prevent the formation of an internal disulfide bond, and alter the structure if it is required for disulfide bond formation. Serine appears to be a reasonable substitution for cysteine because this change would be expected to minimally affect the conformation.

The functions of the three cysteine residues in galactosyltransferase were investigated using site-directed mutagenesis to determine the locations of the disulfide bond and of the sulfhydryl groups. The enzyme remains active when two of its cysteine residues at positions 139 and 205 were mutated separately to serine (92\% and $102 \%)$. However, its enzyme activity was markedly reduced when Cys65 was replaced with serine (27\%). Further substitution of Cys139 or Cys205 with serine did not affect the Cys65Ser mutant galactosyltransferase, as shown in Fig. 3. Our experiments shows that the sulfhydryl group of Cys65 is important required for the catalytic activity of galactosyltransferase.

The above results suggest that the highly conserved amino acids common to bacterial galactosyltransferase are required for proper enzymatic activity. Further studies are under way to characterize the mutant galactosyltransferases. 


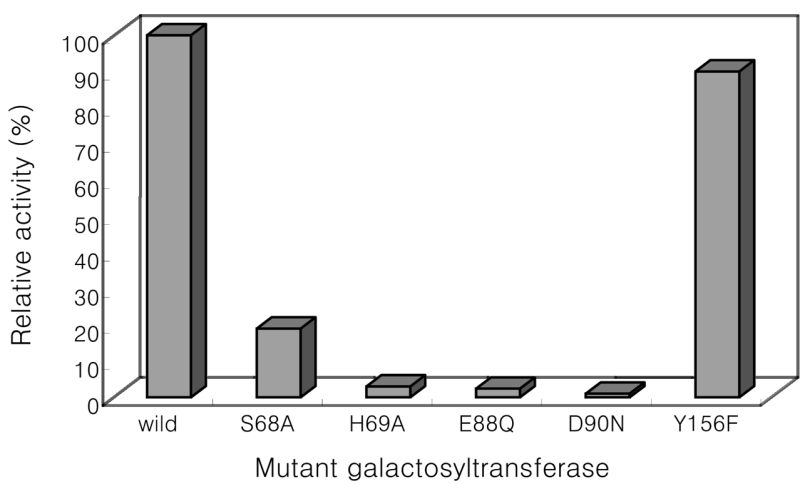

Fig. 2. The galactosyltransferase activity of Neisseria meningitidis $\beta$-1,4-galactosyltransferase and its site directed mutants. The activity detected for the mutant enzyme is indicated as a percentage of the activity of wild-type galactosyltransferase $(0.24$ pmoles of galactose transferred per min per mg protein).

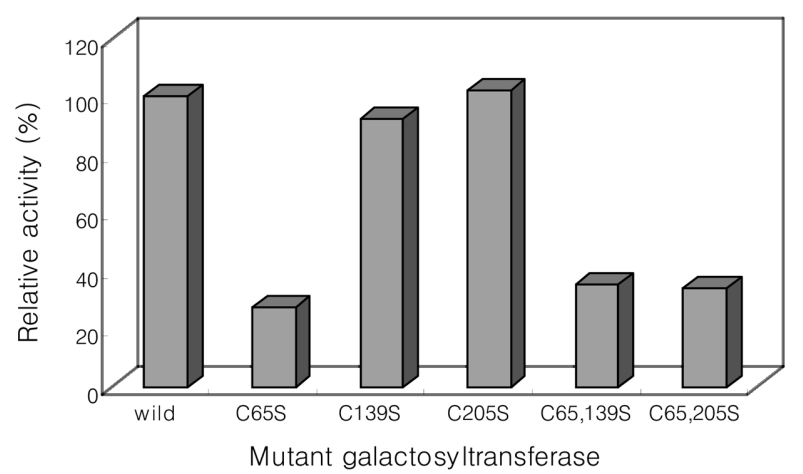

Fig. 3. The galactosyltransferase activity of Neisseria meningitidis $\beta-1,4-$ galactosyltransferase and its cysteine mutants. The activity detected for the mutant enzyme is indicated as a percentage of the activity of wild-type galactosyltransferase $(0.24$ pmoles of galactose transferred per min per mg protein).

Acknowledgments This work was supported by grants from the Korean Science and Engineering Foundation (KOSEF) through the Bio-Medicinal Resource Research Center at Pai Chai University.

\section{References}

Aoki, D., Appert, H. E., Johnson, D., Wong, S. S. and Fukuda, M. N. (1990) Analysis of the substrate binding sites of human galactosyltransferase by protein engineering. EMBO J. 9, 31713178.

Appert, H. E., Rutherford, T. J., Tarr, G. E., Wiest, J. S., Thomford, N. R. and McCorquodale, D. J. (1986) Isolation of a cDNA coding for human galactosyltransferase. Biochem. Biophys. Res. Commun. 139, 163-168.

Boeggeman, E. and Qasba, P. K. (2002) Studies on the metal binding sites in the catalytic domain of $\beta-1,4-$ galactosyltransferase. Glycobiology 12, 395-407.

Breton, C., Bettler, E., Joziasse, D. H., Geremia, R. A. and
Imberty, A. (1998) Sequence-function relationships of prokaryotic and eukaryotic galactosyltransferases. J. Biochem. 123, 1000-1009.

Endo, T., Koizumi, S., Tabata, K. and Ozaki, A. (2000) Cloning and expression of $\beta$-1,4-galactosyltransferase gene from Helicobacter pylori. Glycobiology 10, 809-813.

Gaboriaud, C., Bissery, V., Benchetrit, T. and Mornon, J. P. (1987) Hydrophobic cluster analysis: an efficient new way to compare and analyse amino acid sequences. FEBS Lett. 224, 149-155.

Gotschlich, E. C. (1994) Genetic locus for the biosynthesis of the variable portion of Neisseria gonorrhoeae lipooligosaccharide. J. Exp. Med. 180, 2181-2190.

Heinrichs, D. E., Yethon, J. A. and Whitfield, C. (1998) Molecular basis for structural diversity in the core regions of the lipopolysaccharides of Escherichia coli and Salmonella enterica. Mol. Microbiol. 30, 221-232.

High, N. J., Deadman, M. E. and Moxon, E. R. (1993) The role of a repetitive DNA motif (5-CAAT-3') in the variable expression of the Haemophilus influenzae lipopolysaccharide epitope $\alpha$ Gal ( $\beta$ 1-4) Gal. Mol. Microbiol. 9, 1275-1282.

Higuchi, R., Krummel, B. and Saiki, R. K. (1988) A general method of in vitro preparation and specific mutagenesis of DNA fragments: study of protein and DNA interactions. Nucleic Acids Res. 16, 7351-7367.

Jennings, M. P., Hood, D. W., Peak, I. R., Virji, M. and Moxon, E. R. (1995) Molecular analysis of a locus for the biosynthesis and phase-variable expression of the lacto-N-neotetrose terminal liposaccharide structure in Neisseria meningitidis. Mol. Microbiol. 18, 729-740.

Koh, E., Shim, K., Kim, H-K., Park, K., Lee, S., Kim, J. D., Yoo, S. D., Chi, S. C. and Hong, S. (2001) Cloning, expression, and characterization of protein carboxyl $O$-methyltransferase from porcine brain. J. Biochem. Mol. Biol. 34, 559-565.

Kim, K-S, Kim, C-H, Shin, D-Y and Lee, Y-C (1997) Molecular cloning and expression of cDNAs encoding mouse gal $11,3(4)$ GlcNAc $\alpha 2,3$-sialyltransferase and gal $\beta 1,4(3)$ GlcNAc Q2,3-sialyltransferase. J. Biochem. Mol. Biol. 30, 95-100.

Maniatis, T., Fritsch, E. F. and Sambroch, J. (1982) Molecular Cloning, Cold Spring Harbor, New York, USA.

Masri, K. A., Appert, H. E. and Fukuda, M. N. (1988) Identification of the full-length coding sequence for human galactosyltransferase $\quad(\beta-\mathrm{N}$-acetylglucosaminide: $\quad \beta-1,4-$ galactosyltransferase). Biochem. Biophy. Res. Commun. 157, 657-663.

Masibay, A. S. and Qasba, P. K. (1989) Expression of bovine $\beta$ 1,4-galactosyltransferase cDNA in COS-7 cells. Proc. Natl. Acad. Sci. USA 86, 5733-5737.

Nakazawa, K., Furukawa, K., Narimatsu, H. and Kobata, A. (1993) Kinetic study of human $\beta$-1,4-galactosyltransferase expressed in E. coli. J. Biochem. 113, 747-753.

Narimatsu, H., Sinha, S., Brew, K., Okayama, H. and Qasba. P. K. (1986) Cloning and sequencing of cDNA of bovine $\mathrm{N}$ acetylglucosamine ( $\beta 1-4)$ galactosyltransferase Proc. Natl. Acad. Sci. USA 83, 4720-4724.

Park, J. E., Lee, K-Y., Do, S-I. and Lee, S. S. (2002) Expression and characterization of $\beta$-1,4-galactosyltransferase from Neisseria meningitidis and Neisseria gonorrhoeae. J. Biochem. Mol. Biol. 35, 330-336.

Paulson, J. C. and Colley, K. J. (1989) Glycosyltransferases. structure, localization, and control of cell type-specific 
glycosylation. J. Biol. Chem. 264, 17615-17618.

Potter, M. D. and Lo, R. Y. (1995) Cloning and characterization of a gene from Pasteurella haemolytica A1 involved in lipopolysaccharide biosynthesis. FEMS Microbiol. Lett. 129, 75-81.

Ram, B. P. and Munjal, D. D. (1985) Galactosyltransferases: physical, chemical, and biological aspects. CRC Crit. Rev. Biochem. 17, 257-311.

Shaper, N. L., Hollins, G. F., Douglas, J. G., Kirsch, I. R. and Shaper, J. H. (1988) Characterization of the full length cDNA for murine $\beta$-1,4-galactosyltransferase. Novel features at the 5'end predict two translational start sites at two in-frame AUGs. J. Biol. Chem. 263, 10420-10428.

Sun, S., Schilling B., Tarantino, L, Tullius, M. V., Gibson, B. W. and Munson, R. S. Jr. (2000) Cloning and characterization of the lipooligosaccharide galactosyltrnasferase II gene of Haemophilus ducreyi. J. Bacteriol. 182, 2292-2298.

Yadav, S and Brew, K. (1990) Identification of a region of UDPgalactose: $\mathrm{N}$-acetylglucosamine $\beta$ 4-galactosyltransferase involved in UDP-galactose binding by differential labeling. J. Biol.
Chem. 265, 14163-14169.

Yadav, S. P. and Brew, K. (1991) Structure and function in galactosyltransferase. Sequence locations of $\beta$-lactalbumin binding site, thiol groups, and disulfide bond. J. Biol. Chem. 266, 698-703.

Yuan, Y. P., Schultz, J., Mlodzik, M. and Bork, P. (1997) Secreted fringe-like signaling molecules may be glycosyltransferases. Cell 88, 9-11.

Wakarchuk, W. W., Cunningham, A., Watson, D. C. and Young, N. M. (1998) Role of paired basic residues in the expression of active recombinant galactosyltransferases from the bacterial pathogen Neisseria meningitidis. Protein Eng. 11, 295-302.

Wang, W., Wong, S. S., Fukuda, M. N., Zu, H., Liu, Z., Tang, Q. and Appert, H. E. (1994) Identification of functional cysteine residues in human galactosyltransferase. Biochem. Biophys. Res. Commun. 204, 701-709.

Zu, H., Fukuda, M. N., Wong, S. S., Wang, Y., Liu, Z., Tang, Q. and Appert, H. E. (1995) Use of site-directed mutagenesis to identify the galactosyl transferase binding sites for UDPgalactose. Biochem. Biophy. Res. Commun. 206, 362-369. 